\title{
The Measurement of Heat Release Rates by Oxygen Consumption Calorimetry in Fires Under Suppression
}

\author{
BOGDAN Z. DLUGOGORSKI, JACK R. MAWHINNEY and VO HUU DUC \\ National Research Council, Institute for Research in Construction \\ Ottawa, Ontario K1A 0R6, Canada
}

\begin{abstract}
A series of open-space fire experiments was conducted at the National Fire Laboratory (NFL) to validate the capabilities of the NFL room-size oxygen-consumption calorimeter, and to assess the importance of accounting for actual water vapour content in the exhaust gases in calculating heat release rates (HRR). Water spray was used to partially suppress some of the fires, and to add significantly to the humidity of the exhaust gases. The equations normally used in the fire research community for oxygen calorimeter assume unsuppressed fires, and that water vapour in the exhaust gases is due solely to the humidity of the incoming air and to combustion reactions. This paper derives the basic equations for computing heat release rates based on the principle of nitrogen balance. The general equations take into account all sources of water vapour, including incoming air, combustion reactions, and evaporation due to suppression. The equations are then simplified to i) neglect all humidity, and, ii) consider only the humidity of the incoming air. The predictions of the HRR from the three sets of equations are compared with the HRR calculated for unsuppressed fires and with the HRR obtained by measuring fuel consumption rates. As long as the water vapour content in the exhaust gases is less than $7 \%$, both simplified equations can be used to measure the HRR of partially suppressed fires, without significant error. For larger concentrations of water vapour, water vapour should be measured and the full equations used.
\end{abstract}

KEYWORDS: fire suppression, heat release rate, sprinklered fires, oxygen consumption calorimetry

\section{NOMENCLATURE}

$\underline{\text { Roman symbols: }}$

A

C

$E$

$E^{\infty}$

$M$

$\dot{n}$

$P$

$\dot{q}$

$R$ cross-sectional area of the duct $\left(0.2397 \mathrm{~m}^{2}\right)$

velocity factor ( 0.9 unitless)

heat of combustion per $\mathrm{kmol}$ of consumed oxygen $(419.2 \mathrm{MJ} / \mathrm{kmol}$ of $\mathrm{O}_{2}$ generic, $444.0 \mathrm{MJ} / \mathrm{kmol}$ of $\mathrm{O}_{2}$ for propane)

heat of combustion of $\mathrm{CO}$ per $\mathrm{kmol}$ of consumed oxygen

$\left(563.2 \mathrm{MJ} / \mathrm{kmol}\right.$ of $\mathrm{O}_{2}$ )

molecular weight $(\mathrm{kg} / \mathrm{kmol})$

molar flow rate $(\mathrm{kmol} / \mathrm{s})$

pressure $(\mathrm{Pa})$

heat release rate $(\mathrm{MJ} / \mathrm{s})$

universal gas constant $(8314 \mathrm{~J} / \mathrm{kmol} \mathrm{K})$ 
Greek symbols:

\section{$\Delta \mathrm{P}$}

$\alpha$

$\phi$

Superscripts:

combustion

$e$

$d$

dilution, $i$

Subscripts:

$\mathrm{CO}, \mathrm{CO}_{2}, \mathrm{HC}$, $\mathrm{H}_{2} \mathrm{O}, \mathrm{N}_{2}, \mathrm{O}_{2}$

$i$

total velocity pressure $(\mathrm{Pa})$

expansion factor (unitless, 1.105 generic, 1.084 for propane)

oxygen depletion factor (unitless)

refers to air flowing through the fire zone

refers to exhaust conditions

refers to dry gas

refers to entrained and incoming air, respectively

refers to carbon monoxide, carbon dioxide, total hydrocarbons, water

vapour, nitrogen, and oxygen

refers to $i^{\text {th }}$ component

refers to total or average (e.g., total molar flow)

\section{INTRODUCTION}

A large scale oxygen consumption calorimeter has been constructed at the National Fire Laboratory to measure heat release rates for moderate sized fires between 100 and $3000 \mathrm{~kW}$. The oxygen consumption calorimetry operates on the principle that, for a wide variety of fuels, the heat of combustion per unit mass of the consumed oxygen is approximately constant and, at $25^{\circ} \mathrm{C}$ and $101.3 \mathrm{kPa}$, equal to $419.2 \mathrm{MJ} / \mathrm{kmol}$ of $\mathrm{O}_{2}\left(13.1 \mathrm{MJ} / \mathrm{kg}\right.$ of $\left.\mathrm{O}_{2}\right)$, as first noted by Thornton [1].

From the experimental point of view, the oxygen consumption calorimetry relies on the accurate determination of the amount of oxygen consumed during the burning process, and it requires that both the total flow rate and the oxygen content of the exhaust gases be measured. The method allows no losses of the combustion gases. A knowledge of the concentration of carbon monoxide is also necessary, if combustion is not complete, and an additional correction is required. It should be emphasized that an accurate calculation of the total flow of combustion gases is only possible if the average molecular weight of the exhaust gases is known.

Over the years, for many investigations that involved determination of heat release rates by oxygen consumption calorimetry, the water vapour content of the exhaust gases was not measured; see for example [2,3]. Perhaps, this could be explained by the fact that Parker [4,5] and Janssens [6] (see also an excellent paper by Janssens and Parker [7]) provided expressions for correcting HRR for the presence of water vapour carried with the incoming air and produced by the combustion reaction itself. Deriving the equations, Janssens and Parker [7] made two assumptions: i) the molecular weight of gases in the duct of a calorimeter is the same as the average molecular weight of the incoming air, and ii) the number of moles of combustion products may be correlated with the number of moles of air, whose oxygen was completely depleted during burning. With respect to the latter, the two authors introduced a parameter $\alpha$, called an expansion factor, which remains similar for many fuels.

These assumptions come into serious question, however, for conditions in which water spray is directed into a fire in an attempt to extinguish it. Firstly, the quantity of water present in the exhaust gases will be significantly higher than without suppression. Secondly, some carbon dioxide, dissolved in the run-off water, will not be detected by a calorimeter. Lastly, a fraction of pyrolysates and partially cracked hydrocarbons, which are assumed to burn 
completely in unsuppressed fires, remain unburned in a partially suppressed fire. These unburned pyrolysates are drawn into the calorimeter's fume hood. Since, the density of the water vapour is $38 \%$ lower than the density of dry air, the density of gases in the duct may become appreciably lower than the density of the incoming air. Furthermore, the expansion factor, $\alpha$, becomes poorly defined, because heat transferred from the fire to the sprinkler water generates extra water vapour, and some $\mathrm{CO}_{2}$ is removed with the run-off water.

\section{THEORETICAL CONSIDERATIONS}

\section{Basic Equations}

Assuming a complete combustion (no soot or carbon monoxide is produced), two pieces of information are necessary to calculate the quantity of oxygen consumed in a fire: These are the molar flow rates of nitrogen and oxygen in the exhaust gases collected by a canopy hood $\left(\ddot{n}_{N_{2}}^{e}, \ddot{n}_{O_{2}}^{e}\right)$. From the experimental point of view, $\ddot{n}_{N_{2}}^{e}$ and $\ddot{n}_{O_{2}}^{t}$ are determined by measuring the composition and the total volumetric flow rate of gases in the calorimetric apparatus. For convenience, $\dot{n}_{N_{2}}$ includes inert gases such as argon. For simplicity, fuels considered are those which contain no nitrogen or chlorine, and the production of $\mathrm{NO}_{\mathrm{x}}$ during burning is assumed to be negligible. Under these assumptions, the sum of nitrogen entering the fire zone directly and of that entrained with the combustion products is the same as that flowing into the fume hood.

Referring to Fig. 1, the nitrogen balance in and out of the control surface is written as:

$\dot{n}_{N_{2}}^{i}=\dot{n}_{N_{2}}^{\text {combustion }}+\dot{n}_{N_{2}}^{\text {dilution }}=\dot{n}_{N_{2}}^{e}=\dot{n}_{N_{2}} \cdot$

It is important to stress the fact that it is the flow rate of nitrogen that is used in deriving the basic equations of the oxygen consumption calorimetry, although in the final analysis, $\dot{n}_{\mathrm{N}_{2}}$ is divided out of the equations. As shown in Figs. 1 and 2, in actual experiments, concentrations of $\mathrm{O}_{2}, \mathrm{CO}_{2}$ and $\mathrm{CO}$ are measured on the basis of dry gas (as denoted by superscript $d$ ), since the moisture is removed from the sampling line by the drain and desiccant. On the other hand, the concentration of unburned hydrocarbons (HC) is based on the entire effluent stream. Thus from $\Sigma X_{i}^{e, d}=1$,

$X_{N_{2}}^{e, d}=1-X_{O_{2}}^{e, d}-X_{C O_{2}}^{e, d}-X_{C O}^{e, d}-X_{H C}^{e, d}$, where $X_{H C}^{e, d}=\frac{X_{H C}^{e}}{1-X_{H_{2} O}^{e} O}$.

A knowledge of $\dot{n}_{N_{2}}$, and the composition of the incoming air is sufficient to calculate $\dot{n}_{O_{2}}^{i}$, which is then used to obtain the heat release rate $(\dot{q})$,

$\dot{q}=E\left(\ddot{n}_{O_{2}}^{i}-\ddot{n}_{O_{2}}^{e}\right)$

Note that, in this work, $E$ denotes the heat of combustion per kmol of consumed oxygen. The molar flow rate of nitrogen to the calorimeter is,

$\dot{n}_{N_{2}}=\dot{n}_{\text {total }}^{e, d} X_{N_{2}}^{e, t}=\dot{n}_{\text {total }}^{e}\left(1-X_{H_{2} O}^{e}\right) X_{N_{2}}^{e, d}, \dot{n}_{N_{2}}=\dot{n}_{\text {total }}^{e}\left(1-X_{H_{2} O}^{e}\right)\left(1-X_{O_{2}}^{e, d}-X_{C O_{2}}^{e, d}-X_{C O}^{e, d}-X_{H C}^{e, d}\right)$ 


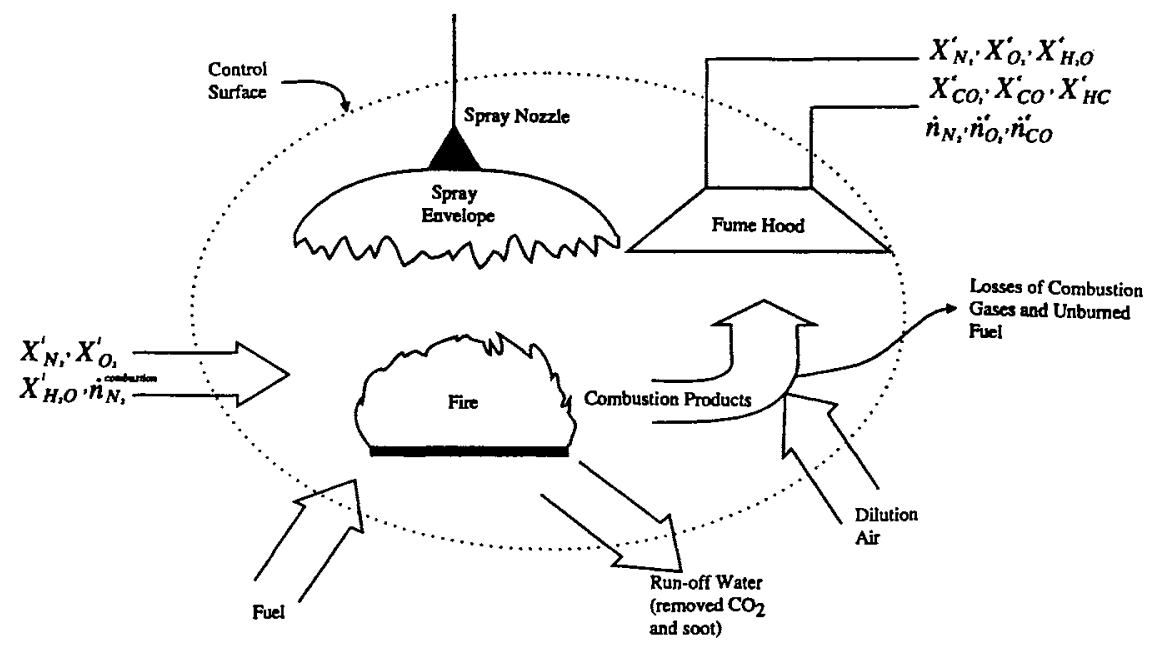

Figure 1. Schematic diagram showing mass balance around the flame zone.

The molar flow rates of oxygen are then obtained from,

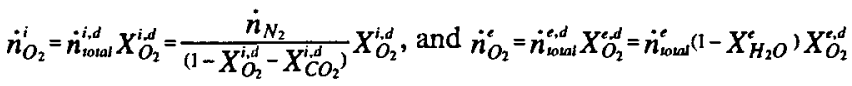

Substituting (4b) into (5a) leads to,

$\dot{n}_{O_{2}}^{i}=\dot{n}_{\text {toat }}^{e}\left(1-X_{H O_{2}}^{e}\right) X_{O_{2}}^{i, d} \frac{i-X_{O_{2}}^{e, d}-X_{C O_{2}}^{e, d}-X_{C O}^{e, d}-X_{H C}^{e, d}}{1-X_{O_{2}}^{i, d}-X_{C O_{2}}^{i, d}}$

If Eqs. $5 \mathrm{a}^{\prime}$ and $5 \mathrm{~b}$ are replaced in Eq. 3 then,

$\dot{q}=E \ddot{n}_{\text {total }}^{e}\left(1-X_{H_{2} O}^{e}\right)\left(X_{O_{2}}^{i, d} \frac{1-X_{O_{2}}^{e, d}-X_{C O_{2}}^{e, d}-X_{C O}^{e, d}-X_{H C}^{e, d}}{1-X_{O_{2}}^{i, d}-X_{C O_{2}}^{i, d}}-X_{O_{2}}^{e, d}\right)$

The accuracy of calculating HRR may be improved if a correction is applied for the incomplete burning of fuel to carbon monoxide. In other words, a correction has to be applied to the heat release rate in Eq. 3. The correction is determined by calculating the HRR as if all consumed oxygen were used to produce $\mathrm{CO}_{2}$ and then subtracting the heat of combustion of $\mathrm{CO}$ multiplied by $0.5 \dot{n}_{\mathrm{CO}}(0.5$ is a stoichiometric coefficient for the reaction $\mathrm{CO}+1 / 2 \mathrm{O}_{2} \rightarrow \mathrm{CO}_{2}$ ), as shown in Eq. 1':

$\dot{q}=E\left(\dot{n}_{O_{2}}^{i}-\dot{n}_{O_{2}}^{e}+0.5 \ddot{n}_{C O}^{e}\right)-0.5 E^{C O} \ddot{n}_{C O}^{e}$, where $\ddot{n}_{C O}^{e}=\dot{n}_{\text {soal }}^{e}\left(1-X_{H_{2} O}^{e}\right) X_{C O}^{e, d}$

The symbol $E^{c 0}$ denotes the heat released during combustion of carbon monoxide per kmole of oxygen. If the effect of $\mathrm{CO}$ on the concentrations of other gases is considered, then a set of HRR equations is written by substituting Eqs. $5 \mathrm{a}^{\prime}, 5 \mathrm{~b}$, and 7 into 1', 


$$
\begin{aligned}
& \dot{q}=\dot{n}_{\text {total }}^{e}\left(1-X_{H_{2} O}^{e}\right)\left[0.5\left(E-E^{c o}\right) X_{C O}^{e, d}+E\left(X_{O_{2}}^{i, d} \frac{1-X_{O_{2}}^{e, d}-X_{C O_{2}}^{e, d}-X_{C O}^{e, d}-X_{H C}^{e, d}}{1-X_{O_{2}}^{i, d}-X_{C O_{2}}^{i, d}}-X_{O_{2}}^{e, d}\right)\right] \\
& M_{\text {total }}^{e}=X_{H_{2} O}^{e O} M_{H_{2} O}+\left(1-X_{H_{2} O}^{e}\right)\left(X_{N_{2}}^{e, d} M_{N_{2}}+X_{O_{2}}^{e, d} M_{O_{2}}+X_{C O_{2}}^{e, d} M_{C O_{2}}+X_{C O}^{e, d} M_{C O}+X_{H C}^{e, d} M_{H C}\right)
\end{aligned}
$$

The purpose of Eq. $8 \mathrm{~b}$ is to stress the intimate relationship between the heat release rate obtained from Eq. 8 a and the average molecular weighi $M_{\text {tota }}^{i}$ of the exhaust gases. In general, $\ddot{n}_{\text {otat }}^{i}$ may only be calculated if $M_{\text {totat }}^{e}$ is known or could be reliably estimated. The issue of determining the average molecular weight is important. The next sub-section describes how to obtain an approximation of $M_{\text {rotat }}^{\text {in }}$ if the concentrations of some of the component gases in the duct are not measured. In this work, the total molar flow rate was computed from the measurements obtained by means of a pitot tube probe. (As shown in Eq. 14, $\dot{n}_{\text {total }}^{c}$ is inversely proportional to the square root of $M_{\text {total }}^{\text {. }}$.) Note that Eqs. 8 a\&b together with Eq. 14 may be considered as the most general set of equations that one may use for the calculation of HRR.

Since Eq. 8 a was obtained from a nitrogen balance using molar flow rates of oxygen and carbon monoxide, $\mathrm{N}_{2}, \mathrm{O}_{2}$, and $\mathrm{CO}$ must not be arbitrarily removed or added to the system, for example by selective scrubbing ahead of the analyzers. However, unburned hydrocarbons or carbon dioxide could be scrubbed from the effluent stream before the analyzers. The point is that scrubbing of one or several of these gases would alter the molar compositions, hence the total molar flow rate, but not the molar flow rates of nitrogen, oxygen, and carbon monoxide. This is why the scrubbing of $\mathrm{CO}_{2}$ from the fire plume by sprinkler water has no effect whatsoever on the computation of heat release rates, provided that Eqs. 8 a\&b and 14 are used with no simplifications. Of course, scrubbing of large amounts of carbon, either in the form of carbon dioxide or soot, could render the calculation of the carbon balance highly inaccurate.

In this investigation, for open-space propane fires, it was noticed that $X_{H C}^{t}$ remained below $320 \mathrm{ppm}$ in the duct. In the case of sprinklered wood crib fires in an enclosed space, Mawhinney observed (unpublished data) that a total hydrocarbon analyzer indicated 1200 $\mathrm{ppm}$, due to the presence of incompletely combusted pyrolysates. A hydrocarbon analyzer, which uses a flame ionization detector, gives a signal that is approximately proportional to the concentration of carbon atoms. (In this work the analyzer was calibrated with propane.) Hence in general, one needs to estimate the average molecular weight of the hydrocarbons, $M_{H C}$, to be substituted in Eqs. $8 \mathrm{a} \& \mathrm{~b}$. It was noted in the experimental results, however, that in unsuppressed fires of liquid and gaseous hydrocarbons in open space, $X_{H C}^{z}$ remains minuscule (below $20 \mathrm{ppm}$ ), and may be safely neglected. Thus in most cases, Eqs. 8 a\&b could be simplified to,

$$
\begin{aligned}
& \dot{q}=\dot{n}_{\text {total }}^{e}\left(1-X_{\mathrm{H}_{2} O}^{e}\right)\left[0.5\left(E-E^{C O}\right) X_{C O}^{e, d}+E\left(X_{O_{2}}^{i, d} \frac{1-X_{O_{2}}^{e, d}-X_{C O_{2}}^{e, d}-X_{C O}^{e, d}}{1-X_{O_{2}}^{i, d}-X_{C O_{2}}^{i, d}}-X_{O_{2}}^{e, d}\right)\right] \\
& M_{\text {total }}^{e}=X_{H_{2} O}^{e} M_{H_{2} O}+\left(1-X_{H_{2} O}^{e}\right)\left(X_{N_{2}}^{e, d} M_{N_{2}}+X_{O_{2}}^{e, d} M_{O_{2}}+X_{C O_{2}}^{e, d} M_{C O_{2}}+X_{C O}^{e, d} M_{C O}\right)
\end{aligned}
$$

Eqs. 9 a\&b are considered as the "basic equations" to which simplifications done in the next section can be related. Their limitations include the lack of correction for unburned hydrocarbons, $\mathrm{HCN}, \mathrm{HCl}$ or $\mathrm{NO}_{\mathrm{x}}$. For most cases, these corrections are negligible, in comparison to the error in measuring of the total volumetric flow rate, which could be in the 
order of $5 \%$. Soot is invariably produced in suppressed fires, but its quantity cannot be determined reliably solely by measurements of the optical density of effluent gases. Some soot is removed by the run-off water, and water vapour may effect obscuration measurements. Even if all soot produced were recorded, no correction, similar to that for $\mathrm{CO}$, would be possible without a knowledge of heats of formation, volatilization, etc., for a fuel.

Finally, two comments must be made. First, heavy gases, such as unburned hydrocarbons, may diffuse from the fire zone at floor level and not be collected by the fume hood. This effect is perhaps minute in unsuppressed fires, due to the existence of entrainment currents and strong plume formation. Since the entrainment structure of a typical fire is destroyed during suppression, however, there is a possibility that a part of the unburned hydrocarbons and carbon dioxide may indeed diffuse away. (It was observed that during runs when propane was released under the hood but not ignited, a significant amount of propane diffused away and was not collected by the hood.) For the same reasons, as explained previously, this effect does alter the predictions of HRR. Secondly, if there is a leak of combustion gases, from the collection hood and exhaust duct, nitrogen is no longer conserved and HRR may be underestimated. If the ambient air is allowed to leak into the dry sampling train, such as line $\# 1$ in Fig. 2, the calculated heat release rates may also be underestimated.

It can be shown by an algebraic manipulation that Eqs. 9 a\&b correspond mathematically to the equations derived by Janssens and Parker [7]. By using molar flow rates (instead of mass flow rates) and expressing $E$ and $E^{C O}$ per $\mathrm{kmol}$ of oxygen (instead of per $\mathrm{kg}$ of oxygen), Janssens and Parker's equations [7] can be written as,

$\dot{q}=\dot{n}_{\text {tootal }}^{i}\left(1-X_{H_{2} O}^{i}\right) X_{O_{2}}^{i, d}\left[E \phi-\frac{1-\phi}{2}\left(E^{C O}-E\right) \frac{X_{C O}^{e, d}}{X_{O_{2}}^{e, d}}\right]$, where,

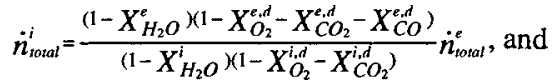

$\phi=\frac{X_{O_{2}}^{i, d}\left(1-X_{C O_{2}}^{e, d}-X_{C O}^{c, d}\right)-X_{O_{2}}^{c, d}\left(1-X_{C O_{2}}^{i, d}\right)}{\left(1-X_{O_{2}}^{e, d}-X_{C O_{2}}^{e, d}-X_{C O}^{e, d}\right) X_{O_{2}}^{i, d}}, M_{\text {lotal }}^{e, t o}$ be used in Eq. 14 is,

$M_{\text {total }}^{e}=X_{\mathrm{H}_{2} \mathrm{O}}^{e} M_{\mathrm{H}_{2} \mathrm{O}}+\left(1-X_{\mathrm{H}_{2} \mathrm{O}}^{e}\right)\left(X_{\mathrm{N}_{2}}^{e, d} M_{\mathrm{N}_{2}}+X_{O_{2}}^{e, d} M_{\mathrm{O}_{2}}+X_{\mathrm{CO}_{2}}^{e, d} M_{\mathrm{CO}_{2}}+X_{\mathrm{CO}}^{e, d} M_{\mathrm{CO}}\right)$.

The parameter $\phi$ in Eq. $10 \mathrm{c}$ is called the oxygen depletion factor. It is noted that Eq. $10 \mathrm{~b}$ computes the molar flow rate of the incoming air $\left(\dot{n}_{\text {total }}^{i},\right)$ for which the water vapour content of the incoming air ( $\left.X_{\mathrm{H}_{2} \mathrm{O}}^{i}\right)$ must be measured. Measurement of water vapour content in this case is redundant, because it can be divided out by substituting Eq. $10 \mathrm{~b}$ into Eq. $10 \mathrm{a}$. In contrast, Eqs. 9 a\&b do not require calculation of the molecular flow rate, nor the humidity, of the incoming air. Eqs. 9 a\&b are therefore easier to use.

\section{Simplifications of the Basic Equations}

Collecting all of the experimental measurements called for in Eqs. 9 a\&b or in 10 a-d is often expensive and time consuming, especially the measurement of water vapour content. However, it is not always necessary to measure the concentration of water vapour. If, for example, the quantity of water evaporated during suppression is in the same order as the 
quantity of water delivered with the incoming air and produced in the combustion process itself, then the measurement of the moisture content in the duct could be avoided. In this section, the basic equations (Eqs. 9 a\&b) are simplified using different assumptions about the water vapour content in the duct. Which of the simplifications is the best to use for experimental work will be addressed in the discussion.

\section{Dry gas}

The combustion products are assumed not to contain any water vapour. Thus Eqs. 9 a\&b are written as,

$\dot{q}=\dot{n}_{\text {total }}^{e}\left[0.5\left(E-E^{C O}\right) X_{C O}^{e, d}+E\left(X_{O_{2}}^{i, d} \frac{1-X_{O_{2}}^{e, d}-X_{C O_{2}}^{e, d}-X_{C O}^{e, d}}{1-X_{O_{2}}^{i, d}-X_{C O_{2}}^{i, d}}-X_{O_{2}}^{e, d}\right)\right]$
$M_{\text {toral }}^{e}=X_{N_{2}}^{e, d} M_{N_{2}}+X_{O_{2}}^{e, d} M_{O_{2}}+X_{C O_{2}}^{e, d} M_{C O_{2}}+X_{C O}^{e, d} M_{C O}$

It is perhaps worthwhile to observe that the dry gas simplification leads to a heavier average molecular weight of the exhaust gases, since water (which the lightest component) is absent from Eq. 11 b. From Eq. 14, it follows that $\dot{q}$ decreases, because $\dot{n}_{\text {toral }}^{e} \propto M_{\text {toral }}^{e-0.5}$ This effect is more than balanced by the fact that $1-X_{H_{2} O}^{e}$ was set to unity in Eq. $11 \mathrm{a}$.

\section{Initial humidity}

This case assumes that the water vapour in the incoming air is the same as in the exhaust gases $\left(X_{\mathrm{H}_{2} \mathrm{O}}^{i}=X_{\mathrm{H}_{2} \mathrm{O}}\right)$. The presence of combustion and evaporated water is neglected. This leads to the following equations,

$$
\begin{aligned}
& \dot{q}=\dot{n}_{\text {roal }}^{e}\left(1-X_{H_{2} O}^{i}\right)\left[0.5\left(E-E^{C O}\right) X_{C O}^{e, d}+E\left(X_{O_{2}}^{i, d} \frac{1-X_{O_{2}}^{e, d}-X_{C O_{2}}^{e, d}-X_{C O}^{e, d}}{1-X_{O_{2}}^{i, d}-X_{C O_{2}}^{i, d}}-X_{O_{2}}^{e, d}\right)\right] \\
& M_{\text {soral }}^{e}=X_{H_{2} O}^{i} M_{H_{2} O}+\left(1-X_{H_{2} O}^{i}\right)\left(X_{N_{2}}^{e, d} M_{N_{2}}+X_{O_{2}}^{e, d} M_{O_{2}}+X_{C O_{2}}^{e, d} M_{C O_{2}}+X_{C O}^{e, d} M_{C O}\right)
\end{aligned}
$$

\section{No suppression}

This case includes the equations derived by Janssens and Parker [7] when water vapour in the exhaust gases is not measured, but estimated as the sum of the humidity of the incoming air and water released during the combustion process. As discussed in the introduction, these equations take no account for evaporated water due to suppression efforts or scrubbed carbon dioxide. Moreover, the density of the exhaust gases is assumed to correspond to the density of the incoming air. After Janssens and Parker [7], for the case in which $\mathrm{O}_{2}, \mathrm{CO}_{2}$ and $\mathrm{CO}$ are measured:

$$
\begin{aligned}
& \dot{q}=\dot{n}_{\text {total }}^{e} \frac{\left(1-X_{\mathrm{H}_{2} O}^{i}\right) X_{O_{2}}^{i, d}}{1+\phi(\alpha-1)}\left[E \phi-\frac{1-\phi}{2}\left(E^{c o}-E\right) \frac{X_{C O}^{e, d}}{X_{O_{2}}^{e, d}}\right] \\
& M_{\text {total }}^{e}=M_{\text {toral }}^{i}=X_{\mathrm{H}_{2} \mathrm{O}}^{i} M_{\mathrm{H}_{2} \mathrm{O}}+\left(1-X_{\mathrm{H}_{2} \mathrm{O}}^{i}\right)\left(X_{N_{2}}^{i, d} M_{N_{2}}+X_{O_{2}}^{i, d} M_{O_{2}}+X_{\mathrm{CO}_{2}}^{i, d} M_{\mathrm{CO}_{2}}\right) .
\end{aligned}
$$

The parameter $\phi$ is given by Eq. $10 \mathrm{c}$. The expansion factor $\alpha$ is defined as the ratio of the number of moles of combustion products to the number of moles of air fully depleted of its oxygen during the combustion process; note that the combustion stream includes nitrogen from the depleted air. For example for $\mathrm{CH}_{4}$, considering 100 moles of incoming air, 
$\mathrm{CH}_{4}+2 \mathrm{O}_{2} \rightarrow \mathrm{C} \mathrm{O}_{2}+2 \mathrm{H}_{2} \mathrm{O}, \alpha=\frac{100-21+1.5 \times 21}{100}=1.105$. This is the value for $\alpha$ recommended by Janssens and Parker [7]. However, under suppression, when $\mathrm{CO}_{2}$ is scrubbed and water vapour added to the exhaust gases, $\alpha$ is undefined.

A similar set of equations (to Eqs. $13 \mathrm{a \& b}$ ) was developed by Janssens and Parker [7] when $\mathrm{CO}_{2}, \mathrm{CO}$ and $\mathrm{H}_{2} \mathrm{O}$ analyzers were absent. These authors made an important assumption, often overlooked, that all $\mathrm{CO}_{2}$ and $\mathrm{CO}$ are removed from the exhaust gases, after the fire zone but before the analyzers. If this assumption is ignored (that is, no carbon dioxide and carbon monoxide are scrubbed from the gas sampling line ahead of the analyzers), the partial pressure of oxygen measured in the calorimeter is underestimated, leading to an underevaluation of $\dot{n}_{\mathrm{O}_{2}}$ and overestimation of the heat release rate. This could result in errors as high as $20 \%$, for the data collected in this investigation. It is recommend that $\mathrm{CO}_{2}$ and $\mathrm{CO}$ analyzers always be used in HRR measurements.

\section{EXPERIMENTS}

\section{General Experimental Set-up}

The oxygen consumption calorimeter in operation at the Factory Mutual Research Corporation served as a model for the construction of the NFL room calorimeter. In comparison, the NFL rig is smaller, being able to accommodate fires up to $3 \mathrm{MW}$. It is composed of a truncated pyramidal hood with a $3.2 \mathrm{~m}$ by $3.9 \mathrm{~m}$ rectangular intake. A rectangular baffle is installed at the inlet to mix the intake gases. A $0.552 \mathrm{~m}$ diameter duct connects the hood to a two speed fan flowing either 2.36 or $4.72 \mathrm{~m}^{3} / \mathrm{s}$. The detailed schematic diagram of the sampling streams including the models of the gas analyzers is presented in Fig. 2.

The centre line velocity in the duct is determined by means of a pitot tube velocity meter rather than by using a bi-directional probe. The pitot tube probe is located at the duct's centre line. For pitot tubes, the local velocity is calculated from the well known expression in which the velocity pressure (difference between dynamic and static pressure readings) is equal to half the product of fluid density and the square of its local velocity. The molar flow rate is then obtained according to the equation:

$\dot{n}_{\text {toal }}^{e}=C A \sqrt{\frac{2 P^{e} \Delta P^{e}}{R T^{e} M_{\text {total }}^{e}}}$.

Where, $C$ is the velocity factor that relates center line to the average velocity (equal to 0.9 ), $A$ denotes the cross-sectional area of the duct, $\Delta P^{e}, P^{e}, T^{e}$, signify velocity pressure, static pressure and temperature in the duct, and $R$ is the universal gas constant. $\Delta P^{e}, P^{e}, T^{e}$ need to be recorded during each experiment. Eq. 14 provides the final expression required for obtaining heat release rates. This expression is used in conjunction with a set of equations chosen from Eqs. 9, 10, 11, 12 or 13. The calculation procedure includes three steps:

1. calculate $M_{\text {tout }}^{e}$ from Eq. 9 b;

2. obtain $\ddot{n}_{\text {toul }}^{e}$ from Eq. 14 ;

3. obtain the heat release rate from Eq. 9 a.

Note that $X_{N_{2}}^{e, d}$ needed in Eqs. $9 \mathrm{~b}, 10 \mathrm{~d}, 11 \mathrm{~b}$, and $12 \mathrm{~b}$, is calculated from $\Sigma X_{i}^{e, d}=1$, whereas $X_{N_{2}}^{i, d}$ required in Eq. $13 \mathrm{~b}$ is determined from $\Sigma X_{i}^{i, d}=1$. 


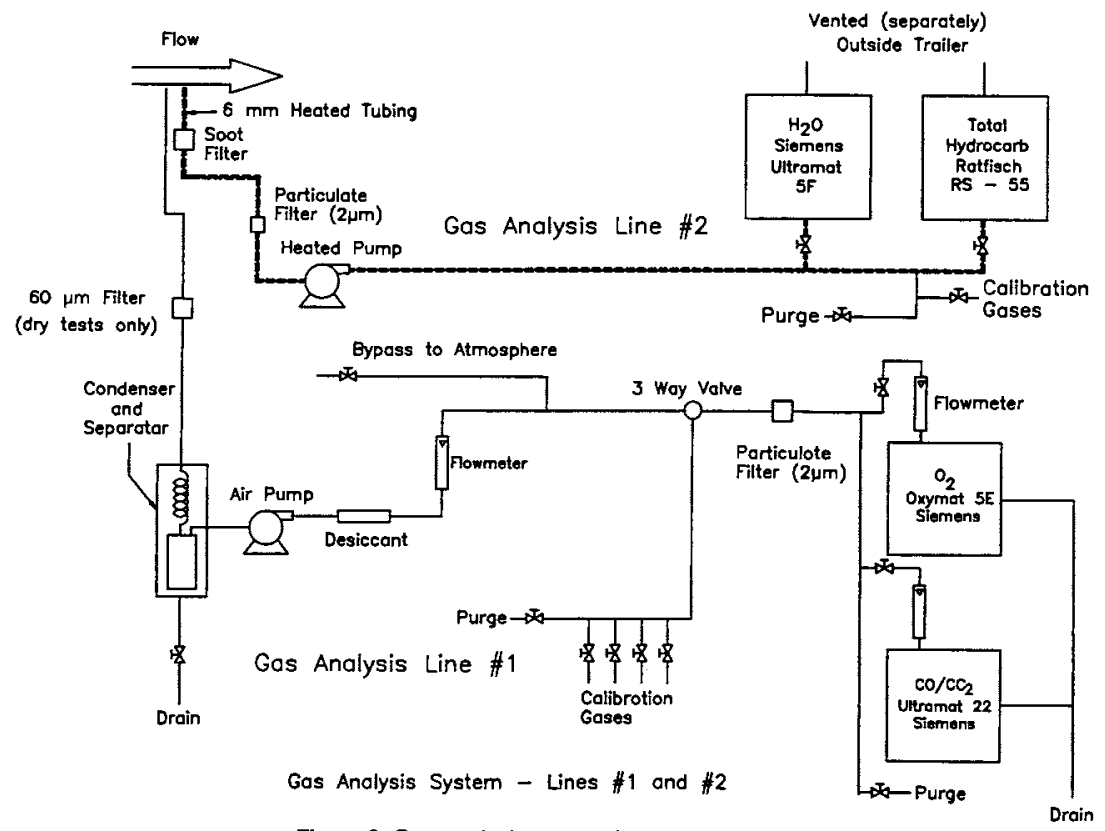

Figure 2. Gas analysis system for oxygen calorimetry.

\section{Experimental Observations and Discussion}

In this study, twelve open-space experiments were conducted. They included free burning and suppression tests with 100-800 kW fires. Premixed and diffusive propane flames, as well as diesel oil pool fires were investigated. Results obtained from one test only are described in this section in detail. These results exhibit intrinsic features of the whole experimental series. The set-up for the test was as follows: A linear diffusive-flame propane burner was secured $0.75 \mathrm{~m}$ above the floor, $2.25 \mathrm{~m}$ below the inlet to the canopy hood. The burner was provided with $0.5 \mathrm{~m}^{3} / \mathrm{min}$. of propane, at $15^{\circ} \mathrm{C}$ and $101.3 \mathrm{kPa}$. A pipe fitted with a single-fluid water mist nozzle discharging $35.3 \mathrm{l} / \mathrm{min}$. of water was placed 1.5 above the burner. Initially, the nozzle sprayed upward to enhance the water evaporation, in the hot gases in the duct, but avoiding flame suppression. Later, the nozzle was turned downward and partial suppression of the flame resulted.

The total quantity of carbon supplied to the system is a sum of carbon delivered with the incoming air in the form of $\mathrm{CO}_{2}$ and that delivered with the fuel. (Carbon dioxide in the incoming air is calculated as $0.041 \%$ of the incoming dry air.) As can be inferred from Fig. 3, this sum is always superior to the entire quantity of carbon measured in the exhaust gases and contributed by $\mathrm{CO}_{2}, \mathrm{CO}$ and unburned hydrocarbons. Soot and a part of the unburned hydrocarbons (which diffuse away at the floor) are not measured in this study may account for the difference. When the water was sprayed in the direction of the burner, the amount of unburned hydrocarbons in the exhaust gases increased, confirming a partial suppression of the flame.

The effect of the sprinkler water and the combustion itself on the molecular flow rate of the water vapour in the duct is shown in Fig. 4. Just after the ignition the quantity of water delivered with the incoming air decreased, although the flow rate of $\mathrm{H}_{2} \mathrm{O}$ in the exhaust 
Time $(\mathrm{min})$

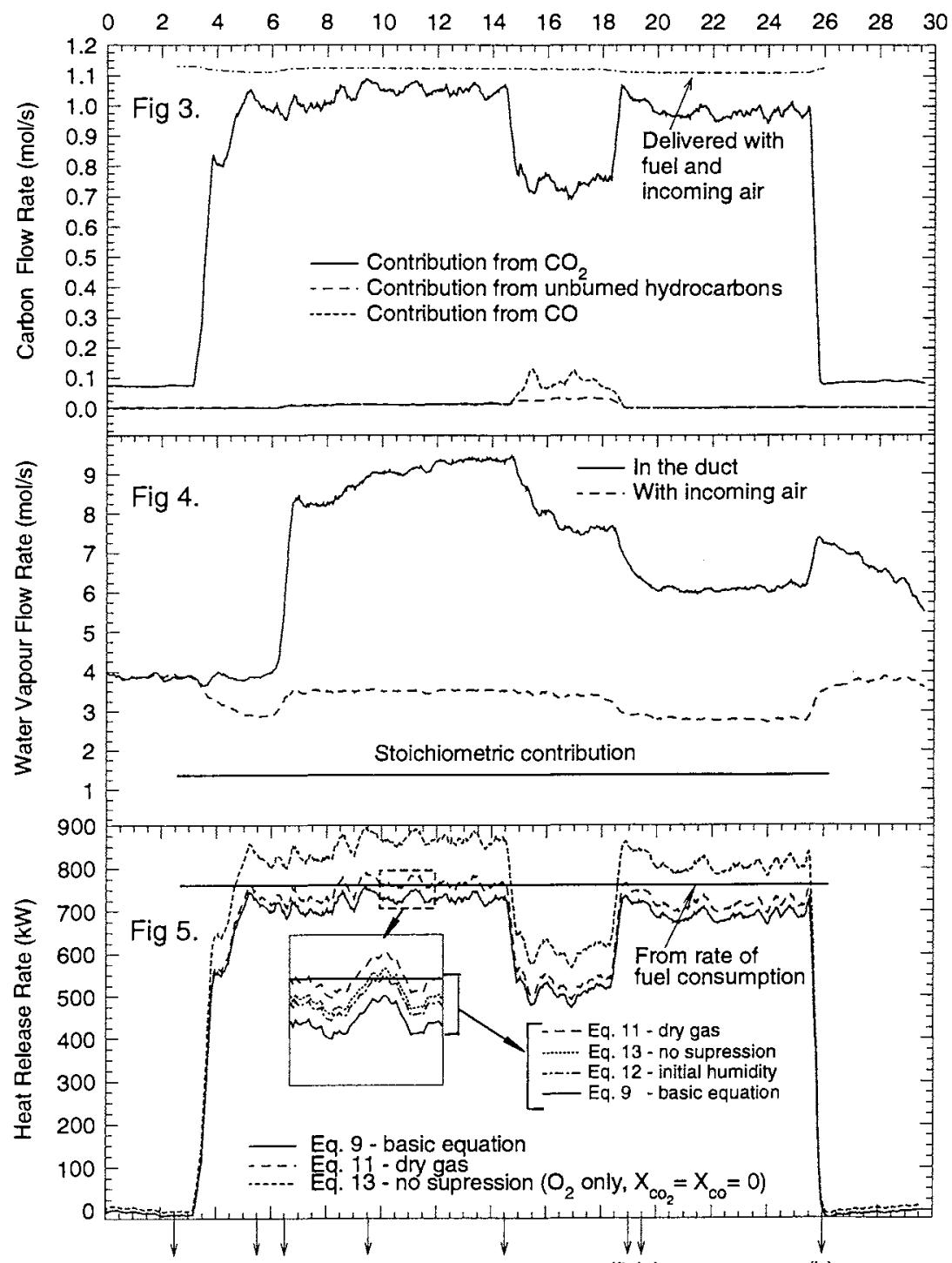

(a)

(b) (c)

(d)

(e)

(f) (g)

(h)

(a) Ignition (b) Finish setting propane flow (c) Vater on nozzle at mid-flame spray up

(d) Propane flow adjusted (e) Nozzle tumed around, spray down (f) Water off

(g) Propane flow adjusted (h) Propane off

Figure 3. Molar flow rates of carbon

Figure 4. Molar flow rates of water vapour

Figure 5. Comparison of calculated heat release rates 
gases was approximately constant. The difference was due to the water vapour produced in the combustion process (see the line denoted "Stoichiometric contribution" in Fig. 4). Note that the volumetric flow rate through the duct was almost steady, but because the temperature of the gases in the duct increased to $140^{\circ} \mathrm{C}$, when there was no spray, the total molar flow rate through the duct dropped. When the spray was activated in the upward direction, the duct temperature diminished to $40^{\circ} \mathrm{C}$, but it increased to $50^{\circ} \mathrm{C}$ when the spray was directed into the burner. At the same time (see Fig. 4, between 14:30 and 19:00 min.), the molecular flow rate of water in the duct decreased, partly as a result of the increased temperature, but more so, it is concluded, because less sprinkler water was being evaporated. In absolute terms, during the test, the water concentration in the exhaust gases was between 1.2 and 6.0 $\%$, reaching $60 \%$ of the saturation concentration.

The predictions of heat release rate from the various equations, which use different assumptions with respect to the water vapour content of the exhaust gases, are plotted in Fig. 5. The solid horizontal line at $766 \mathrm{~kW}$ was obtained by multiplying the propane flow rate by its heat of combustion. The propane flow to the burner did not stop, even though the flame was being suppressed between 14:30 and 19:00 min. However, the flow of propane was not steady and several adjustments of the rotameters were required, in the course of the experimental run. It is estimated that the error in the propane flow and in the variables derived from it, such as the heat release rate, is at least $5 \%$. For this reason, the solid line may only be considered as an indication of the heat expected to be released from the propane in the fire. It is clear in Fig. 5 that this line corresponds well to the calculated heat release rates. It is believed that the HRR predictions from the basic equation (Eq. 9) estimate most closely the true value of the heat release rate, since this equation was derived from the nitrogen balance, using minor assumptions only (no nitrogen and chlorine in the fuel, no production of $\mathrm{NO}_{x}$, negligible mole fraction of unburned hydrocarbons in the exhaust gases). Hence, the predictions from other expressions are evaluated with respect to results obtained from Eq. 9.

It is evident in Fig. 5 that calculations based on measuring oxygen concentration only and no scrubbing of $\mathrm{CO}_{2}$ and $\mathrm{CO}$, lead to a substantial overestimation of the HRR of the fire. Calculations which use either the simplified equations (Eqs. 11 and 12) and Janssens and Parker's no-suppression equation (Eq. 13) consistently overestimate the heat release rates by varying amounts, with respect to the predictions from Eq. 9. The assumption of dry air (Eq. 11) predicts HRR to be higher by around $5 \%$ than the basic equation. Therefore the use of Eq. 11 is discouraged. Eq. 12, which assumes that the water content in the air remains unchanged during combustion, and Eq. 13, which attempts to account for the water released in combustion, appear to be equally accurate in predicting the HRR; see the inset in Fig. 5.

This article described the measurements of heat release rates for open-space fires. For such fires, the concentration of water vapour in the gases in the duct is below $7 \%$, due to dilution of the combustion stream by the ambient air. However, in the case of experiments in test enclosures, the concentration of water vapour could be higher. For example, Kung [8] estimated that a hexane pool fire is sustained if the mole fraction of water in a chamber is below 0.39 (see also [9]). In addition, the concentrations of oxygen, carbon dioxide and carbon monoxide could be different than in this study, due to more significant oxygen depletion and more efficient scrubbing of carbon dioxide by the sprinkler water. We plan to discuss these issues further in a forthcoming publication.

\section{CONCLUSIONS}

The purpose of this work was to determine the effect of water used in suppression of fires on the calculation of heat release rates. An accurate determination of HRR for sprinklered fires in both open and closed spaces is important. Such information is used for developing, testing and validating fire suppression models, for predicting the response time of thermally activated equipment, for justifying the water application rate requirements, and for correlating test 
results from small and large scale experiments. In the course of this investigation, the following conclusions concerning the calculation and experimental determination of HRR in sprinklered fires were reached:

- A nitrogen balance around the fire zone can be conveniently used to obtain general equations for the calculation of heat release rates (Eqs. $8 \mathrm{a} \& \mathrm{~b}$ ).

- The computation of HRR on the basis of the oxygen concentration, with no data collected for concentrations of $\mathrm{CO}_{2}$ and $\mathrm{CO}$, assumes that carbon monoxide and carbon dioxide are scrubbed from the sampled gases before the gases reach the oxygen analyzer. If this assumption is not fulfilled, substantial errors could occur in the estimation of HRR.

- Due to the entrainment of ambient air diluting the combustion products from the unenclosed fires, the water vapour content in the duct is usually below $7 \%$. In general, for open-space fires, the water vapour content does not have to be measured and Eqs. 12 $\mathrm{a} \& \mathrm{~b}$ or $13 \mathrm{a} \& \mathrm{~b}$ may be used for calculations of heat release rates.

- If Eqs. 9 a\&b are used and the composition of gases in the duct is measured, the amount of $\mathrm{CO}_{2}$ scrubbed from the combustion gases by the sprinkler water does not affect the predictions of heat release rates.

- More research is needed for suppressed fires in test enclosures where water vapour concentrations in exhaust may be considerably higher than $7 \%$. Tentatively, it is recommended that heat release rates from such fires be determined from the basic equations (Eqs. $9 \mathrm{a} \& \mathrm{~b}$ ), measuring water vapour content in the duct.

\section{ACKNOWLEDGMENTS}

Helpful discussions with George Crampton and Malgosia Kanabus-Kaminska are acknowledged with gratitude. The authors thank Don Carpenter for assistance in performing the initial experiments and Michael Denham for aiding in plotting of the figures.

\section{LITERATURE CITED}

1. W.M. Thornton, "The Relation of Oxygen to the Heat of Combustion of Organic Compounds", Phil. Mag., 33, 196-203, 1917.

2. R.G. Bill, H.-C. Kung, W.R. Brown, E.E. Hill and R.D. Spalding, "Predicting the Suppression Capabilities of Quick Response Sprinklers in a Light Hazard Scenarios", Fire Prot. Engr., 3: 3, 81-93, 1991.

3. W.D. Walton, "Suppression of Wood Crib Fires with Sprinkler Sprays: Test Results", NBSIR 88-3696, 1-29, Jan. 1988.

4. W.J. Parker, "Calculation of the Heat Release Rate by Oxygen Consumption for Various Applications", U.S. Department of Commerce, National Bureau of Standards, NBSIR 812427, 1-38, Feb. 1982.

5. W.J. Parker, "Calculations of the Heat Release Rate by Oxygen Consumption for Various Applications", J. Fire Sc., 2: Sept./Oct. 1984, pp. 380-395.

6. M. L. Janssens, "Fundamental Thermophysical Characteristics of Wood and their Role in Enclosed Fire Growth", Ph.D. thesis, pp. 3.25-3.38, University of Gent, 1991.

7. M. Janssens and W.J. Parker, "Oxygen Consumption Calorimetry", in Heat Release in Fires, ed. V. Babrauskas and S.J. Grayson, pp. 31-59 Elsevier Applied Science, London, 1992.

8. H.-C. Kung, "Cooling of Enclosed Gas Fires with Water Sprays", J. Heat Trans., 99: Aug., 353-359, 1977.

9. R. Wighus, "Extinction of Enclosed Gas Fires with Water Spray", Proc. 3rd Int. Symp. on Fire Safety Science, 997-1006, 1991. 